\title{
Infrasonic imaging of the Kunlun Mountains for the great 2001 China earthquake
}

\author{
A. Le Pichon, ${ }^{1}$ J. Guilbert, ${ }^{1}$ M. Vallée, ${ }^{1}$ J. X. Dessa, ${ }^{2}$ and M. Ulziibat ${ }^{3}$ \\ Received 22 April 2003; revised 16 June 2003; accepted 24 June 2003; published 12 August 2003.
}

[1] On November 14, 2001, a strong earthquake occurred on the high plateau of western China. At a distance of $1800 \mathrm{~km}$ from the epicenter, coherent infrasonic waves were detected for more than one hour. Using both an inverse location procedure and a complete simulation of the radiated pressure field, distant source regions are accurately located. The seismo-acoustic coupling along a mountain belt is clearly demonstrated. Such an event offers an opportunity to validate velocity models in the atmosphere as well as to improve the understanding of the amplification of ground displacement caused by the topography. INDEX TERMS: 0902 Exploration Geophysics: Computational methods, seismic; 0910 Exploration Geophysics: Data processing; 0994 Exploration Geophysics: Instruments and techniques; 1610 Global Change: Atmosphere (0315, 0325); 3362 Meteorology and Atmospheric Dynamics: Stratosphere/troposphere interactions; KEYWORDS: infrasound, simulation, earthquake, atmospheric coupling, seismic source, CTBTO. Citation: Le Pichon, A., J. Guilbert, M. Vallée, J. X. Dessa, and M. Ulziibat, Infrasonic imaging of the Kunlun Mountains for the great 2001 China earthquake, Geophys. Res. Lett., 30(15), 1814, doi:10.1029/2003GL017581, 2003.

\section{Introduction}

[2] The International Monitoring System (IMS) for the enforcement of the Comprehensive Nuclear-Test-Ban Treaty (CTBT) has been designed to detect and locate nuclear explosions. The global network, which includes radionuclide, hydroacoustic, seismic and infrasound stations, provides an opportunity to monitor human activities and natural phenomena on a global scale. Sources such as shallow earthquakes are known to produce infrasonic pressure waves. Acoustic-gravity waves from the sudden strong vertical ground displacements have been detected at distances of thousands kilometers from the origin [Bolt, 1964; Mikumo, 1968]. Distinct mechanisms of pressure wave generation during large earthquakes have been identified. The vertical displacement of the seismic waves generates locally ground-coupled air waves. The local conversion from seismic waves to the sound pressure has been observed on microbarometers at regional and teleseismic distances [Donn and Posmentier, 1964; Cook, 1971; Takahashi et al., 1994]. Distant generation of infrasonic waves propagating through the atmosphere from the epicenter region have also been detected [Mutschlecner and Whitaker, 1998]. When

\footnotetext{
${ }^{1}$ CEA/DASE, Bruyères-le-Châtel, France.

${ }^{2}$ UNSA-CNRS, UMR Géosciences Azur, Valbonne, France.

${ }^{3}$ Mongolia Academy of Science, Center of Astronomy and Geophysics, Ulaanbaatar, Mongolia.
}

Copyright 2003 by the American Geophysical Union. 0094-8276/03/2003GL017581 the seismic surface waves travel through mountainous regions, the predominant source of infrasound is likely reradiated pressure waves by the topography [Young and Greene, 1982; Le Pichon et al., 2002].

[3] On November 14, 2001, at 09:26:10 UTC, a strong earthquake of magnitude $M_{s} 8.1$ occurred on the mountainous western Chinese region near the Qinghai-Xinjiang border. The earthquake origin $\left(36.0^{\circ} \mathrm{N}, 90.5^{\circ} \mathrm{E}\right.$, focal depth $\sim 5 \mathrm{~km}$ ) was centered along the northern margin of the Tibetan Plateau at the foot of the Kunlun Mountains where substantial surface fault ruptures had occurred (Figure 1). It is likely that the rupture started from the main shock epicenter and propagated eastward along the Kunlun Fault [Van der Woerd et al., 2002]. The main shock was followed by a series of aftershocks that roughly lined up with the surface rupture. During the strong Arequipa earthquake of June 23, $2001\left(M_{w} 8.4\right)$, a detection threshold of infrasonic waves close to $m_{b} 5.8$ has been evaluated for a propagation range of $\sim 500 \mathrm{~km}$ [Le Pichon et al., 2002]. In case of the Kunlun earthquake of magnitude much larger than a detection threshold of $m_{b} 5.5$ [Mutschlecner and Whitaker, 1998], the coherent wave trains detected between 10 and $12 \mathrm{~h}$ UT were likely generated by the main shock at 09:26:10. The large signals generated eased the evaluation of the relative contributions of the different source mechanisms involved in earthquake occurring within a region of high mountains.

[4] The purpose of this paper is to present a thorough analysis of the infrasonic waves generated by this earthquake. At distances of $\sim 1800 \mathrm{~km}$ from the epicenter, large coherent pressure waves were detected for more than one hour at the I34MN infrasound station (Figure 1). Using a precise determination of the arrival times and azimuths of the infrasonic waves and an appropriate velocity model in the atmosphere, the radiating zone is accurately reconstructed. In order to check the consistency of the location of these source regions, a complete simulation of the pressure field radiated from the topography is carried out.

\section{Observations and Wave Parameters}

[5] The wave parameters of the infrasonic waves are calculated with the Progressive Multi-Channel Correlation method (PMCC) [Cansi, 1995]. This method, originally designed for seismic arrays, proved to be very efficient for infrasonic data and is well adapted for analyzing lowamplitude coherent waves within non-coherent noise. With a sampling rate of $20 \mathrm{~Hz}$, the expected numerical resolution at $0.5 \mathrm{~Hz}$ is of the order of $0.5^{\circ}$ for the azimuth and $5 \mathrm{~m} / \mathrm{s}$ for the apparent horizontal phase velocity. Clear variations of azimuth are noted between $180^{\circ}$ and $220^{\circ}$ while the trace velocity ranges from 0.34 to $0.38 \mathrm{~km} / \mathrm{s}$ (Figure 2 ). The main period is around $10 \mathrm{~s}$ with a peak-to-peak amplitude of $\sim 2 \mathrm{~Pa}$. The observed azimuth variations and the long signal 


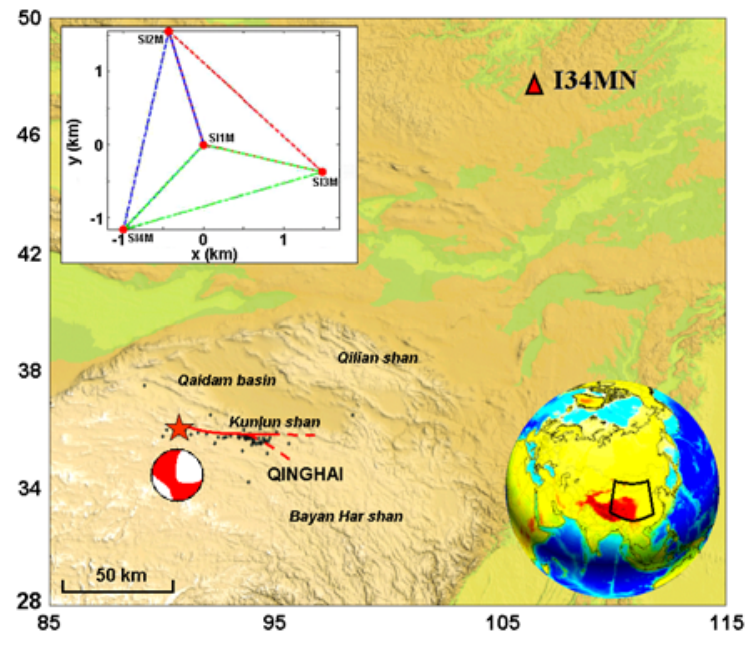

Figure 1. Geographical map (GMT) with the epicenter (star) and its focal mechanism (Havard CMT solution) as delimited by the black outlines on the globe. The distribution of aftershocks (black dots, USGS) is consistent with the Kunlun Fault plane (red line). The I34MN station set up in Mongolia, composed of four microbarometers (SI1M to SI4M) $1.6 \mathrm{~km}$ apart, is part of the global infrasonic network of the IMS $\left(47.8^{\circ} \mathrm{N}-106.4^{\circ} \mathrm{E}\right.$, altitude: $\left.1500 \mathrm{~m}\right)$.

duration are explained by: (i) an extended radiation area along the fault rupture, (ii) the increase of the effective infrasound source region when the seismic surface waves travel from the fault rupture through a region of high mountains and re-radiation occurs.

\section{Infrasound Propagation and Secondary Source Locations}

[6] The input parameters of the location procedure include the measured azimuths and arrival times, the origin time and coordinates of the main shock. The propagation model is based on a constant velocity of $3.3 \mathrm{~km} / \mathrm{s}$ for seismic surface waves propagating from the epicenter area. The atmospheric part is described by sound velocity and wind speed profiles obtained from the time-varying MSISE-90 and HWM-93 empirical reference models [Hedin et al., 1996; Garcés et al., 2002]. Atmospheric infrasonic wave propagation is performed in 3D using ray theory. The equations describing the evolution of the ray canonical variables (slowness vectors, position and propagation time) are numerically solved in spherical coordinates. These equations include the spatio-temporal variations of horizontal wind terms along the ray paths [Virieux and Farra, 1991; Virieux et al., 2003]. In our modeling, the atmospheric conditions of November 14,2002 , are described on a grid ranging from latitude 30 to $50^{\circ} \mathrm{N}$, longitude 85 to $115^{\circ} \mathrm{E}$, altitude 0 to $180 \mathrm{~km}$ and time between 09:30 and 12:00 UTC. The simulations are carried out for infrasonic waves generated from the Kunlun Fault (altitude of $5 \mathrm{~km}$ ) in the 0 to $40^{\circ}$ quadrant, following a shooting procedure. An altitude of $4 \mathrm{~km}$ for the ground level is considered. As shown by Figure $3 \mathrm{~B}$, two dominant wave guides are predicted: (i) thermospheric phases refracted below $120 \mathrm{~km}$ for slowness ranging from 2.7 to $2.9 \mathrm{~s} / \mathrm{km}$, (ii) stratospheric ducted waves refracted below $45 \mathrm{~km}$ for slowness ranging from 2.9 to $3.1 \mathrm{~s} / \mathrm{km}$ - such trapped waves can be observed when the source is located above the station [Weber and Donn, 1982].

[7] The slowness distribution derived from the measured trace velocity presents a maximum between 2.85 and $2.95 \mathrm{~s} / \mathrm{km}$. These values correspond to a celerity of $0.28-$ $0.30 \mathrm{~km} / \mathrm{s}$ (propagation range from the source divided by travel time). The component of the wind transverse to the propagation direction deflects the rays from the original launch azimuth by $\sim 2^{\circ}$. This deviation is taken into account by correcting the measured azimuths. Figure $3 \mathrm{~A}$ reconstructs the distant source regions using a celerity of $0.29 \mathrm{~km} / \mathrm{s}$. The spatial extent of the radiating zone is about

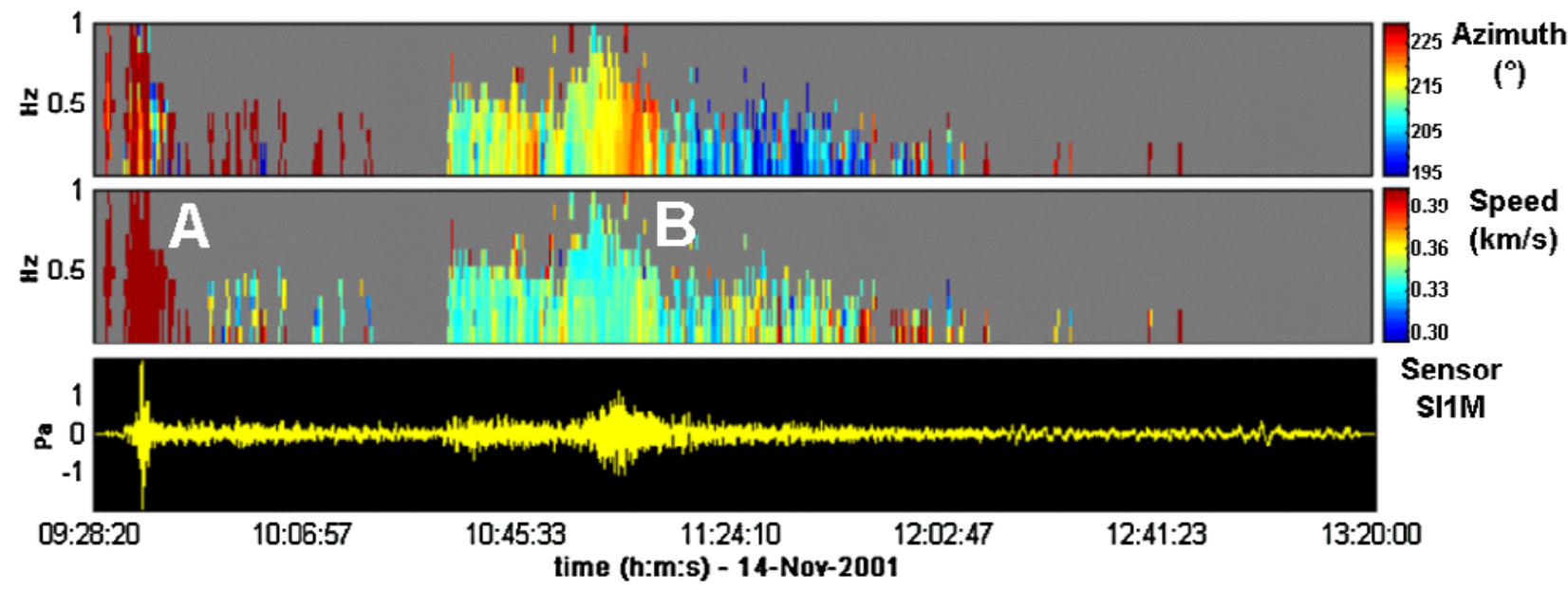

Figure 2. Results of PMCC calculation. The color scales indicate the values of the azimuth and the trace velocity measured at the infrasound station. Azimuths are given with respect to the North. The results are presented from 0.05 to $1 \mathrm{~Hz}$ in 10 equally spaced frequency bands. Bottom: Atmospheric pressure fluctuations recorded at the central element filtered between 0.05 and $4 \mathrm{~Hz}$. In the first part of the signal, coherent wave trains referred as Group A are related to local seismically coupled air waves. Due to the coupling at the earth-air interface, the horizontal trace velocity of the groundcoupled air waves and the seismic waves are identical (greater than $3 \mathrm{~km} / \mathrm{s}$ ). Group B corresponds to the propagation of distant generation of infrasonic waves. 


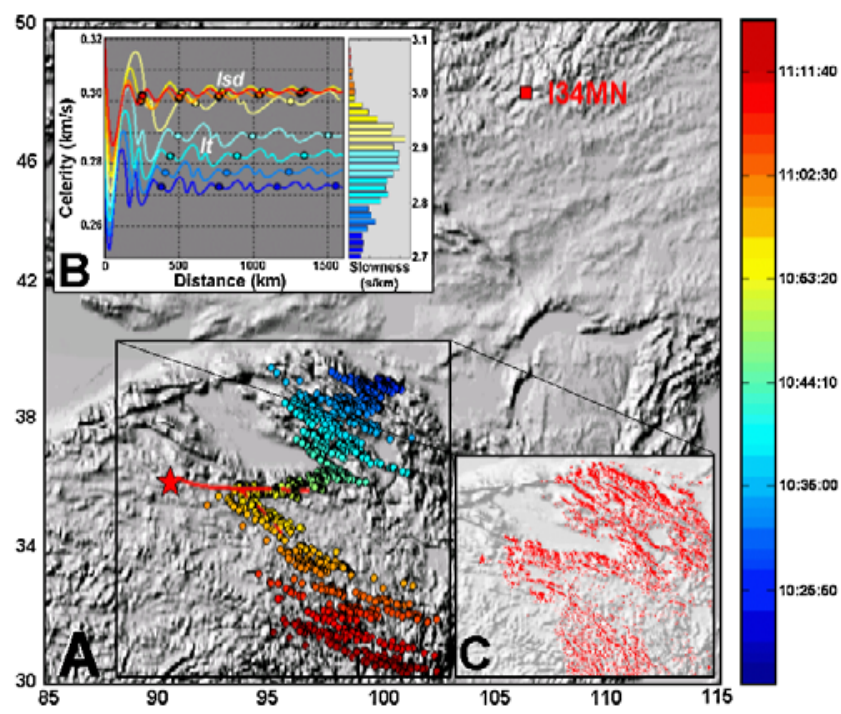

Figure 3. Propagation modeling and location of distant source regions of infrasonic waves (Topography data: ETOPO30). (A) The colored dots indicate the sources location according to the detected arrival times (UTC) of the infrasonic waves. Taking into account uncertainties due to the measurements and the propagation modeling, a maximum location error of $20 \mathrm{~km}$ is estimated for each dot. (B) Predicted celerity models versus slowness and propagation range for a source located at the main shock epicenter. The definition range of the celerity is given by the maximum of the slowness distribution derived from the measured trace velocities (Figure 2). The circles indicate the locations of the ground reception of both ducted stratospheric (Isd phases) and thermospheric paths (It phases). (C) Normalized surface pressure distribution along the Kunlun fault.

$9^{\circ}$ in latitude and $10^{\circ}$ in longitude. The source distributions fall into line with the Qilian range, then border the eastern part of the Qaidam basin and join the Kunlun range. To the south of Qaidam basin, more scattered source distributions follow the Bayan Har mounts.

[8] To confirm these locations, an independent and complete simulation of the radiated pressure field is performed. We first inverse the rupture propagation along the fault using a slip patches model developed by Vallée and Bouchon [2003]. Using this extended rupture model, synthetic seismograms are computed using the discrete wavenumber method [Bouchon, 1981] with a one-dimensional regional crust model. As predicted by Kikuchi and Yamanaka [2001], the source modeling displays a strong directivity. Most of the seismic energy is radiated along the main strike-slip of the fault with a maximum ground velocity found at $\sim 250 \mathrm{~km}$ to the east of the main chock epicenter [Xu et al., 2002; Lin et al., 2002]. The inversion results predict slip values around $1 \mathrm{~m}$ close to the hypocenter and reaching valves slightly greater than $5 \mathrm{~m}$ in the main slip zone. We then consider the acoustic radiation of the topography surrounding the fault. The topography is divided in adjacent strip-line sources radiating energy proportional to the simulated ground velocity [Heil, 1992].

[9] Compared to the wavelength of the seismic surface waves $(\sim 60 \mathrm{~km})$, the area of each source element $\left(3 \times 3 \mathrm{~km}^{2}\right)$ is small enough to consider isophase vibration. According to the frequency of interest $(k L>1, k$ and $L$ defining the acoustic wavenumber and the side of each cell, respectively), source elements radiate essentially simultaneously with a pronounced directivity. Based on this assumption, we divide the topography in adjacent strip-line sources of length $L$ radiating energy proportional to the simulated ground velocity $V_{l}$ normal to each surface element $l$. Considering a distance of observation $R_{l}$ significantly greater than $L$, the Fraunhofer approximation of the Helmholtz-Huygens integral yields: $p_{k}(t)=i L \frac{k \rho c}{2 \pi} \sum_{l=1}^{N} V_{l}\left(t_{l}\right) \Delta h_{l} \frac{e^{-i k R_{l}}}{R_{l}} \frac{\sin \left(k \hat{x}_{l} L / 2\right)}{k \hat{x}_{l} L / 2} e^{-i k c o\left(t-t_{l}\right)}$, where $t_{l}$ is the origin time of each source element, $p_{k}(t)$ is the predicted pressure at the arrival time $t\left(t=t_{l}+\frac{R_{l}}{c_{e f f}}\right), c_{\text {eff }}$ is the celerity in the atmosphere corresponding to the predicted wave guides $(0.29 \mathrm{~km} / \mathrm{s}), \rho$ is the air density, $c o$ is the sound speed, $\Delta h_{l}$ if the height difference of the radiating surface and $\hat{x}_{l}=\sin \left(\theta_{l}\right)$ is given by the angle $\theta_{l}$ between the outward unit normal and the source/receiver vector.

[10] Using the simulated ground velocity and this approximation of the integral formulation, the surface pressure distribution can be calculated. Figure 3 compares the locations of the seismo-acoustic coupling regions (Figure 3C) with those obtained with the inverse location procedure (Figure 3A).

[11] Figure 4 shows the reconstructed azimuth at the station based on the evaluation of the relative contribution to the pressure of each element of the topography. The first part of the azimuth variation is associated with the Qilian Shan range. The apparent scattering of the detection is related to a wide region composed of a succession of ridges, which

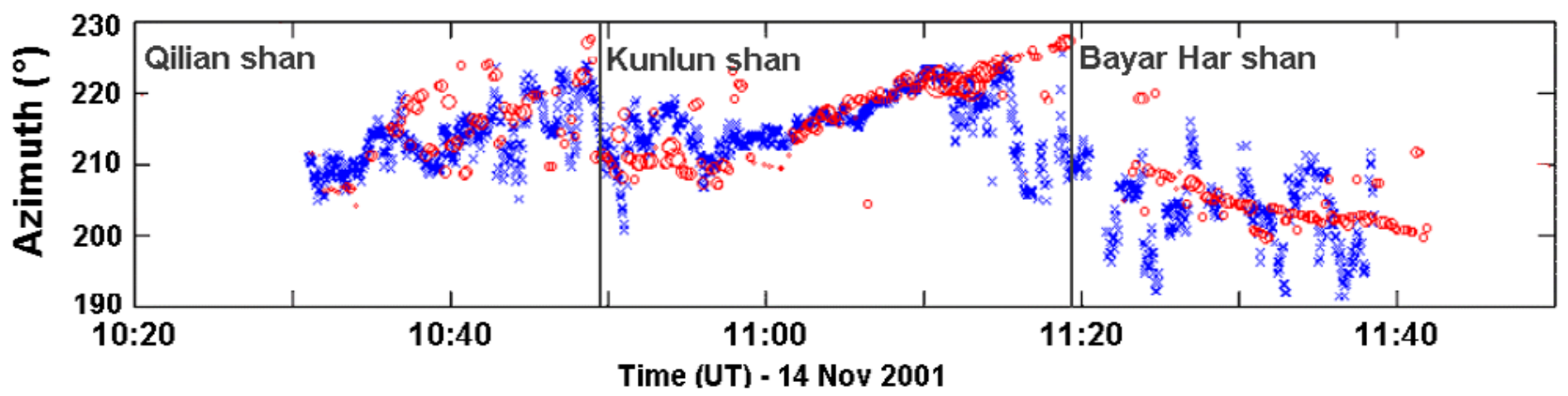

Figure 4. Reconstruction of the azimuth variation at the station. Comparison between the measured (blue crosses) and simulated (red circles) azimuths. The radius of the each circle is proportional to the simulated pressure amplitude radiated by each source element. 
generate simultaneous arrivals with different azimuths. The central part associated with the Kunlun Mountains is more constrained. The small difference of $0.5^{\circ}$ between the measurements and the reconstructed azimuth confirms the validity of the celerity model as well as the wind-corrected azimuths. The last part, associated with the Bayan Har mountains on the Tibetan plateau, is also well simulated even though the amplitude of the infrasonic wave generated by the ground coupling is close to the background noise level.

\section{Conclusion}

[12] The azimuth variations and the expansion of the signal duration suggest that the Kunlun Mountains acted as sources of infrasonic waves over a radiating zone of $\sim 1000 \times 1000 \mathrm{~km}$. The maximum of seismo-acoustic coupling is found to the east of the main shock epicenter, which is consistent with the seismic radiation pattern. The consistency between the measurements and the simulations provided a mean to validate the infrasonic celerity model derived from empirical atmospheric profiles with an uncertainty less than $10 \mathrm{~m} / \mathrm{s}$. For large earthquakes occurring in mountainous regions, infrasonic measurements are valuable for the analysis of the remote effects of earthquakes. Especially, when there is a lack of surface motion instrumentation, infrasonic observations could lead to a rapid determination of the regions where the seismic movements are the largest. Because of the pronounced directivity of the radiation, a complete reconstruction of these source regions could be obtained using more than one infrasound station. Such observations will probably occur more frequently in the future because of the increasing number of IMS stations being deployed. It is hoped that joint studies, combining infrasonic measurements with seismic source characteristics, will allow a better understanding of the physical mechanism involved in the distant generation of infrasonic waves, as well as the amplification of ground displacement due to topography.

\section{References}

Bolt, B. A., Seismic air waves from the great 1964 Alaskan earthquake, Nature, 202, 1095-1096, 1964.

Bouchon, M., A simple method to calculate Greens functions for elastic layered media, Bull. Seism. Soc. Am., 71, 959-971, 1981.

Cansi, Y., An automatic seismic event processing for detection and location: The PMCC method, Geophys. Res. Lett., 22, 1021-1024, 1995.
Cook, R. K., Infrasound radiated during the Montana earthquake of 1959 August 18, Geophys. J. R. astr. Soc., 26, 191-198, 1971.

Donn, W. L., and E. S. Posmentier, Ground-coupled air waves from the great Alaskan earthquake, J. Geophys. Res., 69, 5357-5361, 1964.

Garcés, M., D. P. Drob, and J. M. Picone, A theoretical Study of the effects of geomagnetic fluctuations and solar tides on the propagation of infrasonic waves in the upper atmosphere, Geophys. J. Int., 148, 77-87, 2002.

Hedin, A. E., M. A. Biondi, R. G. Burnside, G. Hernandez, R. M. Johnson, T. L. Killeen, C. Mazaudier, J. W. Meriwether, J. E. Salah, R. J. Sica, R. W. Smith, N. W. Spencer, V. B. Wickwar, and T. S. Virdi, Revised global model of upper thermospheric winds using satellite and groundbased observations, J. Geophys. Res., 96, 7657-7688, 1996.

Heil, C., and M. Urban, Sound fields radiated by arrayed multiple sound sources, paper presented at the 92nd Convention of the Audio Engineering Society, Preprint no 3269, Vienna, 24 - 27 March 1992.

Kikuchi, M., and Y. Yamanaka, Earthquake Information Center, University of Tokyo, http://wwweic.eri.u-tokyo.ac.jp/index-e.html, 2001.

Le Pichon, A., J. Guilbert, A. Vega, M. Garcés, and N. Brachet, Groundcoupled air waves and diffracted infrasound from the Arequipa earthquake of June 23, 2000, doi:10.1029/2002GL015052, 2002.

Lin, A., B. Fu, J. Guo, Q. Zeng, G. Dang, W. He, and Y. Zhao, Coseismic strike-slip and rupture length produced by the $2001 \mathrm{Ms}$ 8.1 Central Kunlun earthquake, Science, 296, 2015-2017, 2002.

Mikumo, T., Atmospheric pressure waves and tectonic deformation associated with the Alaskan earthquake of March 28, 1964, J. Geophys. Res., 73, 2009-2025, 1968.

Mutschlecner, P., and R. Whitaker, Infrasonic observations of earthquakes, Tech. Rep. LA-UR-98-2689, Los Alamos Laboratory, 1998.

Takahashi, Y., Y. Koyama, and T. Isei, In situ measured infrasound at Sapporo associated with an earthquake occurring offshore in southwest Hokkaido on July 12, 1993, J. Acoust. Soc. Jpn., 15, 409-411, 1994.

Vallée, M., and M. Bouchon, Imaging coseismic rupture in far field by slip patches, Geophys. J. Int., in press, 2003.

Van der Woerd, J., A. S. Mériaux, Y. Klinger, F. J. Rterson, Y. Gaudemer, and P. Tapponier, The 14 November $2001, \mathrm{Mw}=7.8$ Kokoxili earthquake in northern Tibet (Qinghai Province, China), Seismol. Res. Lett., 73, $125-134,2002$.

Virieux, J., and V. Farra, Ray-tracing in 3D complex isotropic media: An analysis of the problem, Geophysics, 56, 2057-2069, 1991.

Virieux, J., N. Garnier, E. Blanc, and J. X. Dessa, Paraxial ray tracing for atmospheric wave propagation, J. Acoust. Soc. Am., submitted for publication, 2003.

Weber, M. E., and W. L. Donn, Ducted propagation of Concorde-generated shock waves, J. Acoust. Soc. Am., 71, 340-347, 1982.

$\mathrm{Xu}, \mathrm{X} ., \mathrm{W}$. Chen, W. Ma, G. Yu, and G. Chen, Surface rupture of the Kunlunshan earthquake $(\mathrm{Ms}=8.1)$, Northern Tibetan plateau, Seism. Res. Lett., 73, 884-892, 2002.

Young, J. M., and G. E. Greene, Anomalous infrasound generated by the Alaskan earthquake of 28 March 1964, J. Acoust. Soc. Am., 71, 334$339,1982$.

A. Le Pichon, J. Guilbert, and M. Vallée, CEA/DASE, BP12, 91680 Bruyères-le-Châtel, France.

J. X. Dessa, UNSA-CNRS, UMR Géosciences Azur, 06560 Valbonne, France.

M. Ulziibat, Mongolia Academy of Science, Center of Astronomy and Geophysics, Ulaanbaatar-51, Mongolia. 